\title{
Preparação e caracterização de microcápsulas de poli (ureia-formaldeído) preenchidas com diciclopentadieno
}

\section{Preparation and characterization of poly (urea-formaldehyde) microcapsules filled with dicyclopentadiene}

\author{
Wanessa Rejane Knop ${ }^{1}$, Márcia Margarete Meier ${ }^{1}$, \\ Sérgio Henrique Pezzin ${ }^{1}$
}

\begin{abstract}
${ }^{1}$ Programa de Pós-Graduação em Ciência e Engenharia de Materiais (PGCEM) - Universidade Estadual de Santa Catarina (UDESC), Campus Universitário Prof. Avelino Marcante, CEP: 89.219-710, Joinville, SC, Brasil.

e-mail: wrknop@yahoo.com.br; mmeier.udesc@ gmail.com; $\underline{\text { sergio.pezzin@udesc.br }}$
\end{abstract}

\begin{abstract}
RESUMO
As microcápsulas que contêm agentes de cura têm sido utilizadas para desenvolver compósitos poliméricos com propriedades auto regenerativas. Este trabalho tem como objetivo a produção e caracterização de microcápsulas de poli (uréia-formaldeído), PUF, contendo diciclopentadieno, que satisfaz os requisitos para um material de auto cura para resinas epoxídicas. Uma série de microcápsulas de PUF foram sintetizadas utilizando diferentes parâmetros do processo, incluindo o tipo e concentração de surfactante, o método e a velocidade de agitação. As microcápsulas foram caracterizadas por microscopia eletrônica, análise térmica (DSC, TG) e espectroscopia no infravermelho (FTIR). A distribuição do tamanho e o diâmetro médio das microcápsulas foram determinados por difração a laser. Os resultados mostram que os parâmetros do processo afetam diretamente o tamanho e a morfologia das microcápsulas. Pela seleção da taxa de agitação, foi possível produzir microcápsulas com diâmetros entre 1 e $100 \mu \mathrm{m}$.
\end{abstract}

Palavras chaves: poli (uréia-formaldeído), diciclopentadieno, auto cura, microcápsulas

\section{ABSTRACT}

Microcapsules containing curing agents have been used to develop polymer composites with self-healing properties. This work aims the production and characterization of microcapsules of poly (ureaformaldehyde), PUF, containing dicyclopentadiene, which satisfies the requirements for the self-healing of epoxy resins. A series of PUF microcapsules was synthesized using different process parameters, including the type and concentration of surfactant, and the stirring method and speed. The microcapsules were characterized by scanning electron microscopy, thermal analysis (DSC, TG) and infrared spectroscopy (FTIR). The size distribution and the average diameter was determined in a particle size analyzer by laser diffraction. The results show that the process parameters directly affect the size and morphology of the microcapsules. By the selection of the stirring rate, microcapsules were produced in the diameter range of 1$100 \mu \mathrm{m}$.

Key words: poly (urea-formaldehyde), dicyclopentadiene, self-healing, microcapsules

\section{INTRODUÇÃO}

O emprego mundial de materiais de engenharia tem crescido exponencialmente nos últimos anos, alcançando patamares de 20 milhões de tonelada/ano, com uma diversidade de aplicações e tem ganhado destaque na indústria aeroespacial. No entanto, uma das principais preocupações é quanto a integridade estrutural do composto, pois as matrizes poliméricas são sujeitas a rachaduras e fissuras internas devido ao impacto, intempéries, cargas ou fadiga. Estas microfissuras, em escala milimétrica, são difíceis de serem detectadas e reparadas e nem sempre são perceptíveis. Isto torna o compósito suscetível a falhas, fazendo-se necessário 
realizar reparos periódicos ou até mesmo uma substituição precoce do mesmo, que em muitas situações ésbastante onerosa e, dependendo da finalidade de uso do compósito, pode vir a tornar-se uma catástrofe [14].

O desenvolvimento de materiais autorregeneráveis oferece um enorme potencial para reparação destes danos, pois estes proporcionam a capacidade de cura autônoma, ou seja, são materiais inteligentes que reparam pequenos danos sem a necessidade de detecção ou intervenção manual [5-8]. As matrizes epoxídicas são um destes materiais autorregeneráveis, nos quais são incorporados um agente de autocura líquido microencapsulado e um catalisador disperso na matriz, proporcionanado a formação de ligações cruzadas entre a matriz e o agente de autocura. A autorregeneração também deve se basear em uma estratégia adequada para que a polimerização do agente de autocura ocorra no plano da fratura. O surgimento de uma ruptura ou fissura no polímero provoca o rompimento da microcápsula, liberando o agente de autocura no plano da fratura através da ação capilar, fechando (ou selando) a trinca ao polimerizar-se quando entra em contato com o catalisador [7]. A polimerização do agente de autocura (DCPD) se dá pela abertura do anel que pode ser iniciada por um catalisador de Grubbs. O mecanismo de rompimento da microcápsula na ponta da fissura oferece controle específico de reparação autonômica [9].

A autocura por meio de microencapsulação tem sido usada por diversos autores $[\underline{1}, \underline{5}, \underline{8}-\underline{11}]$ com o objetivo de reparar materiais poliméricos termorrígidos. O sistema de autocura baseado em microcápsulas de uréia-formaldeído contendo diciclopentadieno (DCPD) é preparado por polimerização in situ de uma emulsão óleo-em-água, sendo que este sistema atende aos requisitos de autocura para resinas epoxídicas. O método de polimerização in situ de uréia-formaldeído (PUF) apresenta altos rendimentos e facilidade de preparação [12]. A seleção apropriada de parâmetros no processo de síntese de microcápsulas como o pH, temperatura, tipo e concentração de surfactante e velocidade de agitação, podem influenciar nas características e propriedades da autorreparação da matriz epoxídica [10].

Apesar dos trabalhos apresentados acima abordarem separadamente algumas variáveis no processo de preparação das microcápsulas, não há um estudo sistemático dos efeitos da alteração de parâmetros combinados na preparação de microcápsulas preenchidas com DCPD. Assim, este trabalho teve como objetivo analisar a combinação dos seguintes parâmetros de síntese de microcápsulas de PUF: velocidade de agitação e tipo de surfactante. As melhores condições de síntese foram utilizadas para produzir microcápsulas de PUF contendo diciclopentadieno.

\section{MATERIAIS E MÉTODOS}

\subsection{Materials}

Uréia, formalina (37\% de formaldeído em água), cloreto de amónio, e dodecil sulfato de sódio foram obtidos de Cinetica Química Ltda. Resorcinol e 1-octanol foram obtidos da Vetec Ltda. Diciclopentadieno e o surfactante etileno-anidrido maleico (EMA) foram obtidos da Sigma-Aldrich.

\subsection{Métodos}

Foram testadas três diferentes técnicas para preparação de microcápsulas por polimerização in situ em óleo (diciclopentadieno) e água utilizando um procedimento modificado de BROWN, et al. [్] e BLAISZIK, et al. [1]. Nos dois primeiros métodos foram preparadas microcápsulas sem a incorporação do agente regenerativo. No primeiro método foi utilizado o surfactante dodecil sulfato de sódio (SDS) e agitação magnética por três minutos com sonificação por sonda (Sonics, 750 watts), enquanto no segundo método utilizou-se o surfactante etileno-anidrido maleico (EMA) e agitação mecânica a 800rpm durante 4 horas. No terceiro método foi incorporado o agente regenerativo DCPD e surfactante SDS com agitação mecânica a 800rpm durante 4 horas. A Tabela 1 resume as condições experimentais utilizadas.

As microcápsulas foram caracterizadas quanto às suas características morfológicas, propriedades físicas, estabilidade química e térmica e composiçao química. A morofologia das microcápsulas foi avaliada por microscopia eletrônica de varredura (MEV), em um equipamento ZEISS modelo DSM 940 A. As amostras foram recobertas com uma fina camada de ouro e analisadas a $15 \mathrm{kV}$. Análises de espectroscopia no infravermelho (FTIR) foram realizadas em um espectrofotômetro Perkin Elmer Spectrum One no intervalo de $550-4000 \mathrm{~cm}^{-1}$ (modo ATR, 32 scans).

As análises de calorimetria exploratn.wikipedia.org/ (DSC) e anYPERLINK "http://en.wik (TGA) foram realizados em um equipamento Netzsch modelo STA 449C utilizando taxa de aquecimento de $10^{\circ} \mathrm{C} /$ min em $\mathrm{N}_{2}$. A determinação do tamanho de partículas foi realizada por difração a laser, equipamento 
Cilas, modelo 1064L. As amostras foram preparadas na forma de suspensão com 10\% em massa do teor de sólidos, sendo utilizada água como meio dispersor.

Tabela 1: Parâmetros de processo utilizados na preparação das microcápsulas.

\begin{tabular}{|c|c|c|c|}
\hline Nome do Grupo & Surfactante & Agitação & Presença de DCPD \\
\hline Ocas-SDS & $\begin{array}{c}0,23 \% \text { SDS(surfactante dodecil } \\
\text { sulfato de sódio)/ } \mathrm{H}_{2} \mathrm{O}\end{array}$ & $\begin{array}{c}\text { Magnética com sonificação, } \\
\text { intensidade de } 40 \%, 3 \text { minutos }\end{array}$ & Ausente \\
\hline Ocas-EMA & $\begin{array}{c}50 \mathrm{ml} 2,5 \% \text { EMA(etileno } \\
\text { anidrido maleico) } / \mathrm{H}_{2} \mathrm{O}\end{array}$ & Mecânica a $800 \mathrm{rpm}$ & Presente \\
\hline Preenchidas-SDS & $\begin{array}{c}0,3 \% \text { SDS(surfactante dodecil } \\
\text { sulfato de sódio)/ } \mathrm{H}_{2} \mathrm{O}\end{array}$ & Mecânica a $800 \mathrm{rpm}$, & \\
\hline
\end{tabular}

\section{RESULTADOS E DISCUSSÃO}

\subsection{Morfologia das microcápsulas}

Foram realizadas análises de microscopia eletrônica de varredura para as microcápsulas obtidas com diferentes tipos de agitação e surfactantes. As imagens de MEV são apresentadas na Figura 1 e revelam que as microcápsulas apresentam formato esférico independentemente da condição de preparo. Na Figura 1 observa-se que no grupo Ocas-EMA (Fig. 1a) ocorre agregação das microcápsulas, provavelmente devido à baixa concentração de surfactante EMA para a sua formação. Este mesmo resultado foi identificado por BLAISZIK, et al. [1]], que observou a aglomeração das microcápsulas utilizando agitação mecânica de 800rpm e sonificação por 3 minutos a $40 \%$ de intensidade e 1,5\% de EMA em solução aquosa.

Nas micrografias da Figura 1-b e d é possível observar uma grande variedade de tamanhos de microcápsulas para um mesmo grupo experimental. Tal fato se dá em função do processo de agitação da solução, em que um fluxo maior de agitação ocorre próximo às pás da hélice, predominando a formação de microcápsulas de tamanhos menores, e na região de fluxo menor, longe da hélice, escalas maiores de tamanho dominam. Este resultado corresponde ao comportamento verificado por BROWN, et al. [5]].

A Fig. 1-c apresenta as microcápsulas preparadas sob agitação magnética e sonificação por 3 minutos com intensidade de $40 \%$ (Ocas-SDS) com tamanho na ordem de 2 a $3 \mu \mathrm{m}$, similar ao tamanho das microcápsulas preparadas utilizando somente agitação mecânica (Ocas-EMA), conforme a Fig. 1-d.

A polimerização de UF pode ser catalisada por ácido ou base, em que a queda drástica do $\mathrm{pH}$ leva a um rápido aumento na taxa de polimerização e a viscosidade aumenta, sendo que essas rápidas mudanças de viscosidade na interface do óleo e água afeta a formação das microcápsulas. A tensão superficial interfacial foi o fator predominante no controle da morfologia da superfície das microcápsulas [1]. Isso pode explicar o tipo de microcápsulas produzidas no grupo Ocas-EMA (Tab.1) que apresentaram nanopartículas aglomeradas na superfície de microcápsulas, provavelmente devido ao aumento rápido da taxa de polimerização e considerando que a área superficial destas nanopartículas ulsuperior a urea superficial da microcápsula, a quantidade de surfactante foi insuficiente para mantê-las desagregadas. 


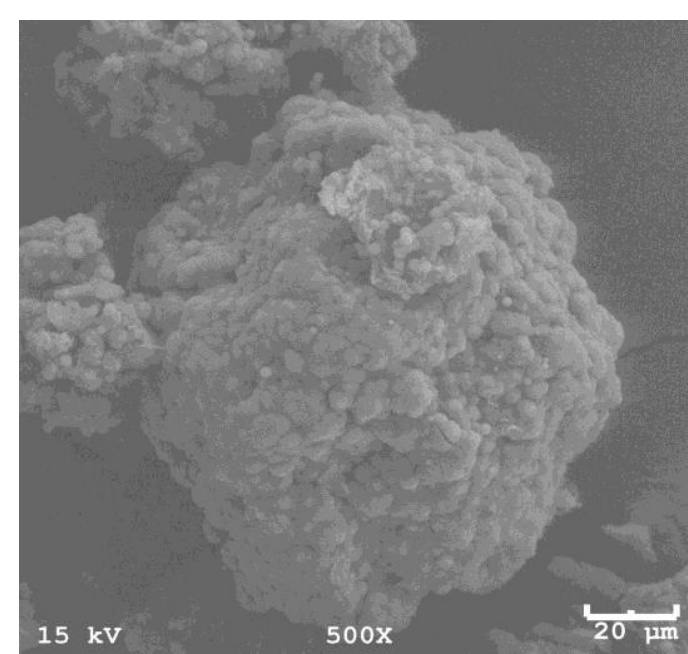

(a)

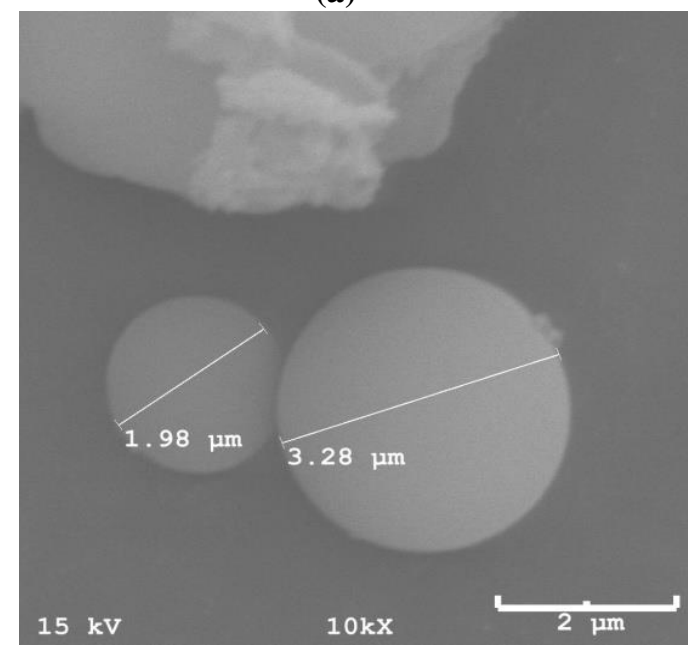

(c)

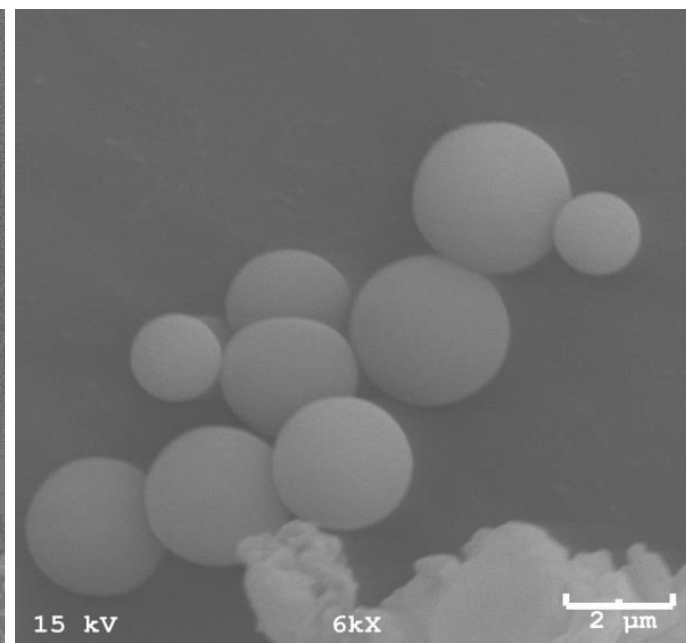

(b)

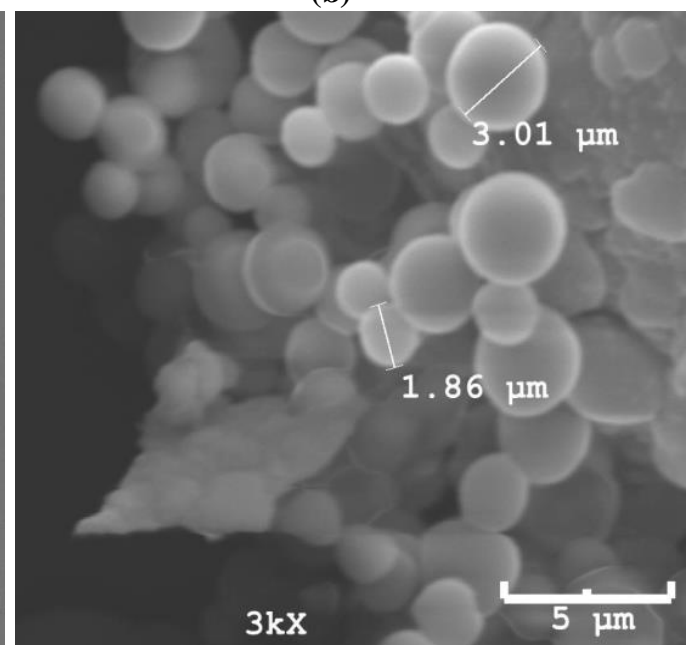

(d)

Figura 1: Imagens obtidas por MEV. (a) Ocas EMA (b) Ocas SDS; (c) Ocas SDS; (d) Preenchidas SDS.

\subsection{Espectroscopia no Infravermelho}

A composição das microcápsulas foi caracterizada por FTIR, sendo que os espectros das microcápsulas poli(uréia-formaldeído) - (PUF) e das microcápsulas de PUF contendo diciclopentadieno (DCPD) -s(PUFDCPD) estão mostrados na Figura 2.

No espectro de PUF, curva A, é possível identificar as seguintes bandas representativas: 1547, 1624 e $3251 \mathrm{~cm}^{-1}$. As bandas de $1624 \mathrm{e} 1547 \mathrm{~cm}^{-1}$ são atribuídas aos grupos funcionais de amidas primárias e secundárias da resina uréia-formaldeído. Segundo ZHAOGUO, et al.[13] a absorção da banda em torno de 1645 $\mathrm{cm}^{-1}$ estáeassociada a grupos $\mathrm{C}=\mathrm{O}$, enquanto a banda a $1550 \mathrm{~cm}^{-1} 1$ aatribuída a grupos $-\mathrm{C}-\mathrm{N}$-. Estas são as bandas características atribuídas ao PUF, material do invólucro polimérico que formou as microcápsulas. As bandas a $3251 \mathrm{~cm}^{-1}$ (curva A) e $3344 \mathrm{~cm}^{-1}$ (curva B) estão atribuídos aos estiramentos dos grupos $-\mathrm{OH} \mathrm{e}-\mathrm{NH}$, respectivamente, da poli (uréia-formaldeído) [12,14]. Baseado no estudo de YUAN et al. [14], que realizou espectroscopia no infravermelho somente para o DCPD, observou-se a banda de estiramento de $=\mathrm{C}-\mathrm{H}$ a 3060 $\mathrm{cm}^{-1}$, banda de estiramento de C-H em $2.971 \mathrm{~cm}^{-1}$, e a deformação angular do grupo =C-H em cerca de 1340 $\mathrm{cm}^{-1}$, indicando que as bandas apresentadas na curva B de 3035, 2972, $1342 \mathrm{~cm}^{-1}$ referem-se aos modos vibracionais dos grupos de $\mathrm{C}=\mathrm{C}, \mathrm{C}-\mathrm{H}$ e $=\mathrm{C}-\mathrm{H}$, característicos do DCPD. CHUANJIE [12] também identificou valores semelhantes para as bandas de C=C-H em $3000-3100 \mathrm{~cm}^{-1} \mathrm{e}-\mathrm{C}-\mathrm{H}$ a $2800-2974 \mathrm{~cm}^{-1}$. 


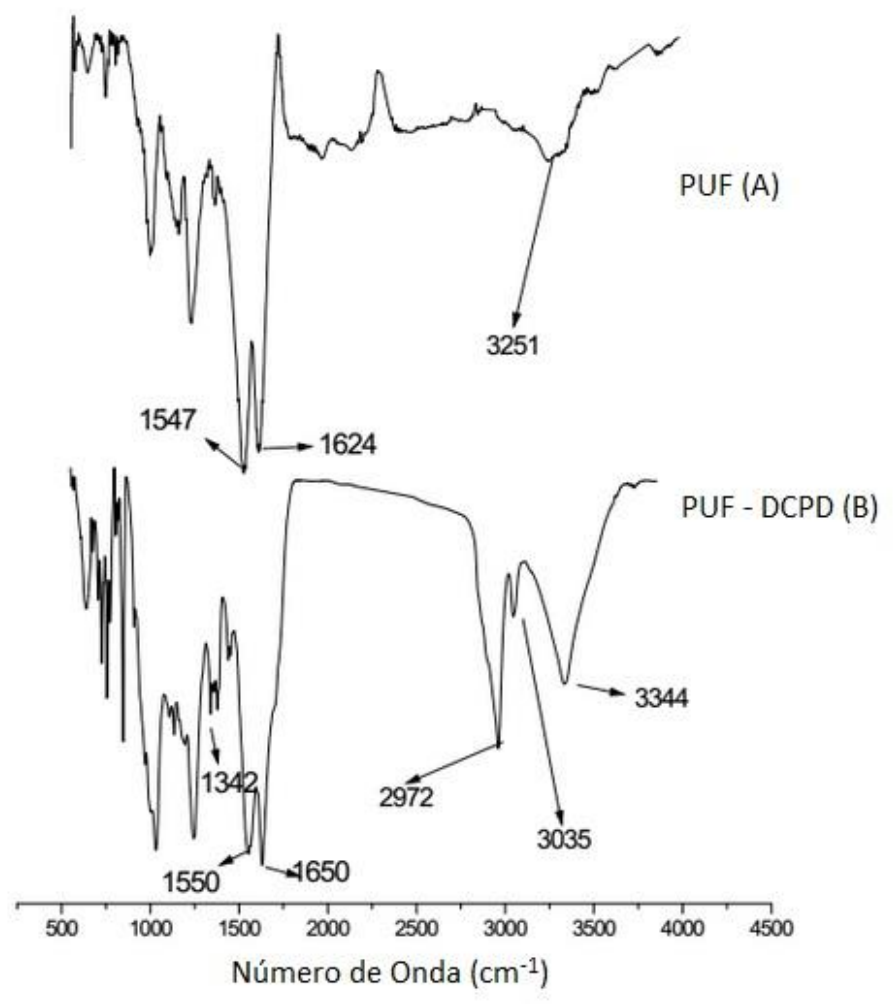

Figura 2: Espectro na região de infravermelho do invólucro das microcápsulas de PUF (curva A) e do invólucro das microcápsulas de PUF com DCPD incorporado (curva B).

\subsection{Distribuição de tamanho das microcápsulas}

As microcápsulas apresentaram uma ampla faixa de distribuição de tamanho, compreendida entre 0,24 e 318,4 $\mu \mathrm{m}$. Uma distribuição de tamanhos de microcápsulas entre 1,15 e $258,2 \mu \mathrm{m}$ foi obtida com sonificação por 3 minutos e surfactante SDS. O diâmetro mais frequente (moda) na amostra analisada das microcápsulas foi 91,1 $\mu \mathrm{m}$ (Figura 3). Para agitação mecânica e EMA a distribuição de tamanhos de microcápsulas foi entre 0,450 e $318,41 \mu \mathrm{m}$. O diâmetro mais frequente (moda) na amostra analisada das microcápsulas foi 112,2 $\mu \mathrm{m}$.

Uma distribuição de tamanhos de microcápsulas entre 0,24 e 138,2 $\mu \mathrm{m}$ foi obtida para a amostra com agitação mecânica e surfactante SDS acima da concentração micelar crítica. Neste caso, o diâmetro mais frequente (moda) na amostra analisada das microcápsulas foi $39,6 \mu \mathrm{m}$, o que mostra uma distribuição mais estreita de tamanho de partículas. Além da distribuição de tamanho de partículas esta análise fornece a média de distribuição de volume que é expressa como d(0,5), que expressa o valor abaixo do qual se encontra $50 \%$ da amostra, enquanto d(0,9) expressa o tamanho de partícula abaixo do qual estão $90 \%$ da amostra [15]. Desta forma os valores de $\mathrm{d}(0,5)$ e $\mathrm{d}(0,9)$ para os grupos Ocas-SDS, Ocas-EMA e Preenchidas-SDS respectivamente são $64,8 \mu \mathrm{m}$ e $142,6 \mu \mathrm{m} ; 66,1 \mu \mathrm{m}$ e $170,3 \mu \mathrm{m} ; 27,3 \mu \mathrm{m}$ e $63,2 \mu \mathrm{m}$.

Com o aumento da concentração de surfactante SDS, a distribuição de tamanho de microcápsulas torna-se estreita e o diâmetro médio das microcápsulas diminui, o que é consistente com os resultados relatados por outros pesquisadores [10]. O aumento da concentração de surfactante reduz a tensão superficial da fase contínua diminuindo assim o tamanho das microcápsulas [16].

Como o modo de agitação (sonificação ou agitação mecânica) não influenciou significativamente na distribuição granulométrica optou-se em sintetizar as microcápsulas preenchidas com DCPD sob agitação mecânica. Por sua vez, o surfactante selecionado foi SDS em função da dispersão adequada das partículas geradas. Para garantir essa dispersão foi elevado teor de SDS em relação ao grupo de microcápsulas ocas. 


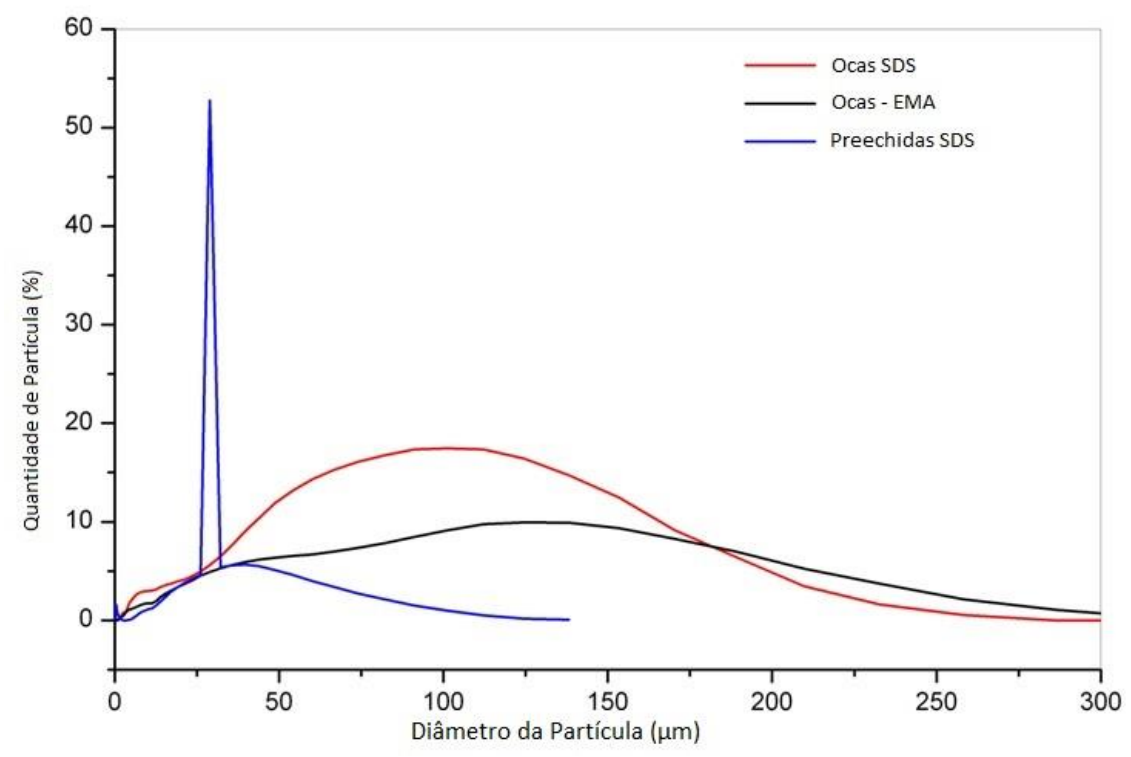

Figura 3: Distribuição de tamanhos de microcápsula dos grupos Ocas SDS, Ocas EMA e Preenchidas SDS.

\subsection{Análise Térmica}

A Figura 4 apresenta os resultados da análise térmica para as microcápsulas ocas em comparação às microcápsulas preenchidas com o DCPD.

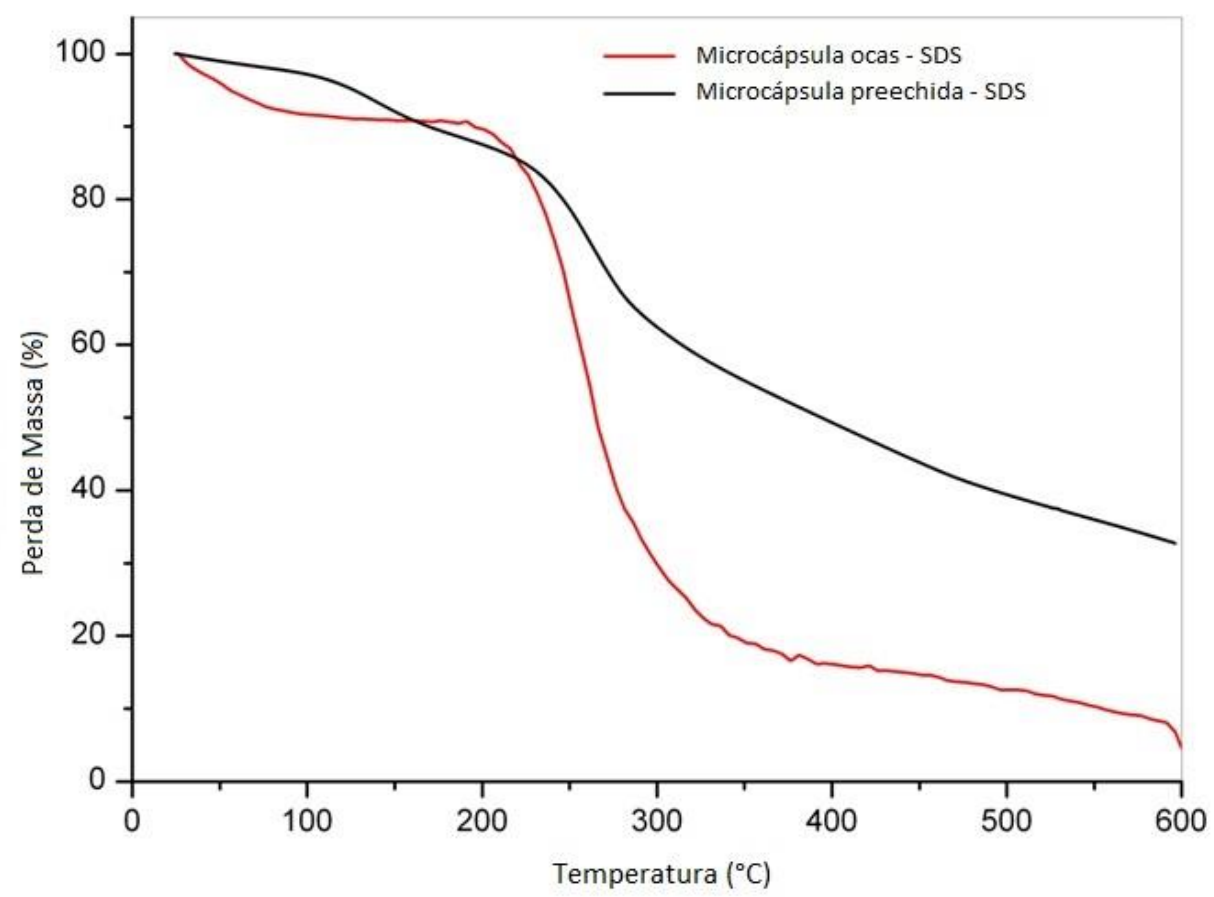

Figura 4: Curvas de TGA com taxa de $10^{\circ} \mathrm{C} / \min$ em $\mathrm{N}_{2}$ das microcápsulas de uréia e formaldeído e das microcápsulas incorporadas com diciclopentadieno.

Na curva de TGA das microcápsulas ocas observam-se três intervalos de perda de massa: o primeiro entre 25 a $100{ }^{\circ} \mathrm{C}$; o segundo entre 180 e $170{ }^{\circ} \mathrm{C}$ e um terceiro estágio entre 370 a $600{ }^{\circ} \mathrm{C}$. A primeira perda de massa está relacionada principalmente àeeliminação de água residual e formaldeído livre. A segunda etapa de perda de 
massa de $72,6 \%$ ocorre principalmente devido à decomposição do polímero PUF e continua a ocorrer até $600{ }^{\circ} \mathrm{C}$ com perda de 9,5\%. Resultados similares foram encontrados por LIAO et al. e LI et al., 2007.

Ao analisar a curva de TGA das microcápsulas preenchidas-SDS também observa-se 3 etapas de decomposição térmica. A primeira etapa ocorre entre 25 a $150{ }^{\circ} \mathrm{C}$, também associada a volatilização de água e resíduos monoméricos. Considerando que a temperatura de fusão de DCPD ocorre em cerca de $33{ }^{\circ} \mathrm{C}$ e ebulição em $\quad 174{ }^{\circ} \mathrm{C}[\underline{3}, \underline{12}, 15]$, a segunda etapa $\left(150\right.$ a $\left.300{ }^{\circ} \mathrm{C}\right)$, com perda de massa de $29,6 \%$, está associada a dois fenômenos: a volatilização do DCPD e a decomposição das cadeias poliméricas de PUF. Devido a ocorrência destes dois fenômenos na mesma faixa de temperatura não foi possível determinar o teor de DCPD incorporado nas microcápsulas. Uma terceira etapa de decomposição ocorre e é associada a decomposição do polímero PUF.

Comparando as faixas de temperatura de degradação da microcápsula oca e preenchida verifica-se deslocamento das temperaturas e modificação do teor de resíduo presente a $600{ }^{\circ} \mathrm{C}$. Essa diferença no teor de resíduo indica que a presença de DCPD interfere na cinética de decomposição do PUF. As temperaturas de degradação das microcápsulas não são exatamente as mesmas que as dos componentes individuais, sugerindo a ocorrência de uma reação entre a microcápsula e o núcleo induzida termicamente durante a decomposição.

Figura 5: Curva de DSC das microcápsulas Preenchidas-SDS $\left(10^{\circ} \mathrm{C} / \mathrm{min} \mathrm{em} \mathrm{N}_{2}\right)$.

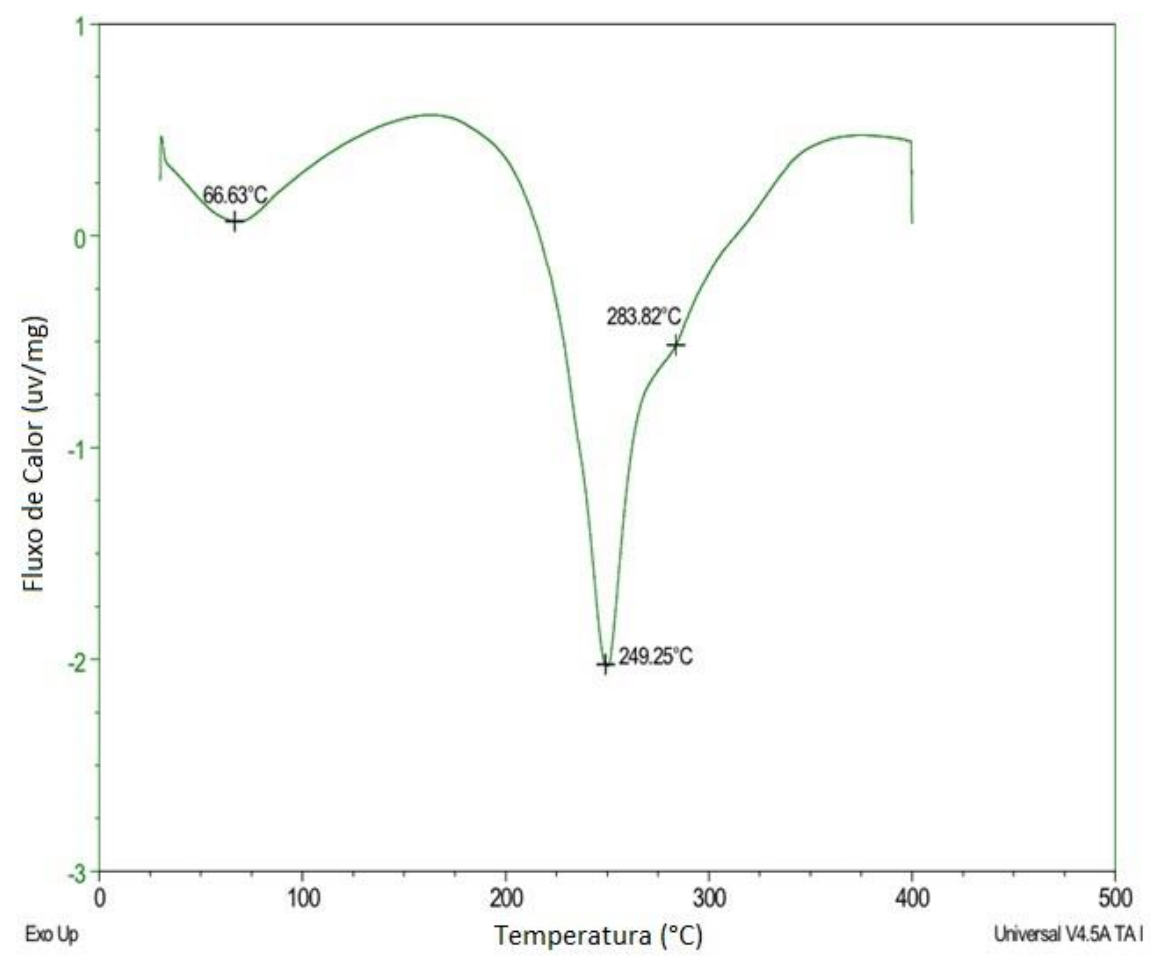

A curva de DSC (Figura 5) indica dois sinais endotérmicos com picos em 66 e $249{ }^{\circ} \mathrm{C}$ com um ombro em $283^{\circ} \mathrm{C}$. O primeiro sinal endotérmico está provavelmente relacionado à perda de massa por volatilização de água conforme discutido no TGA. O segundo sinal endotérmico inicia em aproximadamente $170{ }^{\circ} \mathrm{C}$, temperatura na qual o DCPD entra em ebulição, e é caracterizado por um pico intenso a $249{ }^{\circ} \mathrm{C}$, o qual está de acordo com o observado na termogravimetria para o processo de degradação das microcápsulas do PUF.

\section{CONCLUSÕES}

O estudo foi baseado na caracterização das microcápsulas sintetizadas com e sem diciclopentadieno incorporado com variação no modo de agitação, teor e tipo de surfactante. As características morfológicas e a análise de tamanho de partículas revelaram que as microcápsulas apresentam formato esférico e uma grande gama de tamanhos, sendo que o tamanho da microcápsula pode ser controlado pela taxa de agitação. Os tamanhos das microcápsulas encontrados com a utilização do surfactante EMA e SDS foram bem similares, enquanto que com a incorporação de diciclopentadieno obteve-se tamanhos bem menores devido ao aumento do teor de surfactante. 
Desta forma o surfactante SDS acima da concentração micelar critica apresentou melhor resultado para preparação das microcápsulas utilizando a agitação mecânica para formação de microcápsulas com maiores tamanhos e a utilização combinada de agitação mecânica e sonicação com sonda para formação de microcápsulas com variação de tamanho menores. Os espectros de FTIR mostram as bandas características de DCPD e PUF o que indica que DCPD foi eficientemente microencapsulado em poli(uréia-formaldeído). A análise térmica confirmou a presença de diciclopentadieno nas microcápsulas e demonstrou a modificação das temperaturas de degradação do polímero em presença de DCPD.

\section{BIBLIOGRAFIA}

[1] BLAISZIK, B.J., SOTTOS, N.R., WHITE, S.R., et al., Nanocapsules for self-healing materials", Composites Science and Technology, v. 68, n.3-4, pp. 978-986, 2008.

[2] MICHAUD, V. J. et al., "Performance of self-healing epoxy with microencapsulated healing agent", Polymer, v. 50, n. 23, pp. 5533-5538, 2009.

[3] XIAO, D. S., YUAN, Y. C., RONG, M. Z., "Self-healing epoxy based on cationic chain polymerization", Polymer, v. 50, n. 13, pp. 2967-2975, 2009.

[4] BERGENDORFF, C., SCIEN CENTRAL, http://www.sciencentral.com/articles/. Acessado em: 12 de novembro de 2011.

[5] BROWN, E. N. et al., "In situ poly(urea-formaldehyde) microencapsulation of dicyclopentadiene", $J$. Microencapsulation, v. 20, n. 20, pp. 719-730, 2003.

[6] WU, D. Y., MEURE, S., SOLOMON, D., et al., lation,maldehyde) microencapsulation of dicyclopenta”, Progress in Polymer Science, v. 33, n. 5, pp. 479-522, 2008.

[7] TIARKS, F., LANDFESTER, K., ANTONIETTI, M., "Preparation of polymeric nanocapsules by miniemulsion polymerization”, Langmuir, v. 17, n. 3, pp. 908-918, 2001.

[8] RULE, J. D., SOTTOS, N. R., WHITE, S. R., "Effect of microcapsule size on the performance of selfhealing polymers", Polymer, v. 48, n. 12, pp. 3520-3529, 2007.

[9] WHITE, S., SOTTOS, N., GEUBELLE, P., “Autonomic healing of polymer composites”, Nature, v. 409, pp. 2005-2008, 2001.

[10] YUAN, L., GU, A., LIANG, G. "Preparation and properties of poly(urea-formaldehyde) microcapsules filled with epoxy resins”, Materials Chemistry and Physics, v. 110, pp. 417-425, 2008.

[11] ZHAOGUO, J., et.al., "Synthesis and properties of paraffin capsules as phase change materials", Polymer, v. 49, pp. 2903-2910, 2008.

[12] CHUANJIE, F., XIAODONG, Z., "Preparation and barrier properties of the microcapsules added nanoclays in the wall”, Polymers for Advanced Technologies, v. 20, n. 12, pp. 934-939, 2009.

[13] BLAISZIK, B. J. et al., "Microcapsules filled with reactive solutions for self-healing materials", Polymer, v. 50, n. 4, pp. 990-997, 2009.

[14] YUAN, Li., et al., "Synthesis and characterization of microencapsulated dicyclopentadiene with melamine - formaldehyde resins", Colloid \& Polymer Science, v. 285, n.7, pp. 781-791, 2007.

[15] MOLTALVO, M. E. D. A., Escoamento de emulsões óleo em água através de micro-capilares, Dissertação de M.Sc., Pontifícia Universidade Católica do Rio de Janeiro, Rio de Janeiro, RJ, Brasil, 2008.

[16] LI, M. et al., "Microencapsulation by solvent evaporation: State of the art for process engineering approaches”, International Journal of Pharmaceutics, v. 363, pp. 26-39, 2008. 